\title{
Primeira descrição de singamose brônquica ocorrida no Estado do Espírito Santo
}

\author{
First description of human bronchial syngamosis \\ in the State of Espírito Santo
}

\section{Beatriz Bergamini Sossai ${ }^{1}$, Rodrigo Leal Silva Bussular ${ }^{1}$, Paulo Mendes Peçanha ${ }^{1}$, Carlos Urbano Gonçalves Ferreira Júnior ${ }^{1}$ e Paulo Augusto Sessa²}

\begin{abstract}
RESUMO
Relatamos o caso de um homem de 48 anos, que evoluiu durante 4 meses com quadro de tosse seca associada à dor torácica. Após serem descartadas as etiologias mais prováveis, realizou-se uma broncofibroscopia que revelou a presença de um casal de Syngamus laringeus no brônquio do lobo superior esquerdo. O paciente tornou-se assintomático após a retirada do nematóide.
\end{abstract}

Palavras-chaves: Singamose. Tosse seca. Dor torácica.

\section{ABSTRACT}

We report the case of a 48-year-old man who presented progressive dry cough associated with chest pain over a four-month period. After ruling out the most probable etiologies, bronchofibroscopy was performed and showed a pair of Syngamus laringeus inside the left upper lobe bronchus. The patient became asymptomatic after the nematodes had been removed.

Key-words: Syngamosis. Dry cough. Chest pain.

Syngamus laryngeus, ou Mammomonogamus laryngeus, é um nematóide parasita do sistema respiratório do gado bovino, búfalos e caprinos. Ocasionalmente, é encontrado no homem. Tem cor vermelha ou vermelho-amarronzada devido à hematofagia, e macho e fêmea vivem permanentemente em cópula. Por ser 0 macho menor (cerca de $3 \mathrm{~mm}$ de comprimento) do que a fêmea (cerca de $8,5 \mathrm{~mm}$ ) e a vulva situar-se no terço anterior do corpo da fêmea, o casal de vermes assume a forma de um "y".

A fêmea fecundada põe ovos que chegam ao meio exterior diretamente com as secreções da árvore respiratória, ou em mistura com as fezes após serem deglutidos. Em poucos dias no solo, larvas infectantes eclodem desses ovos e, para darem continuidade aos seus ciclos de vida, necessitam ser ingeridas por seus hospedeiros naturais. Uma vez na luz do tubo digestivo, essas larvas penetram em vasos sanguíneos da mucosa, passam pela circulação porta hepática e alcançam a rede capilar dos pulmões. Transpõem, então, a parede alveolar e migram para seus hábitats definitivos, onde completam o crescimento e a maturidade sexual. A fêmea começa a ovipor cerca de três semanas após o acasalamento. No homem, a infecção e a evolução do parasita ocorrem da mesma maneira ${ }^{7113}$.

Entretanto, devido aos curtos intervalos de tempo transcorridos entre as datas prováveis das infecções e o surgimento dos sintomas, observados em alguns pacientes, que foram de 6 a 11 dias, é também admitida a hipótese do ser humano infectarse com os vermes adultos. Nestes casos, os vermes expelidos diretamente para o meio exterior pelos hospedeiros naturais chegariam à faringe do homem junto com água ou alimentos, de onde migrariam para a laringe e daí para os pulmões ${ }^{1217}$.

0 primeiro caso de infecção humana por Syngamus laryngeus foi descrito por Leiper em $1913^{8}$, nas Antilhas. Em 1921, Travassos ${ }^{16}$ registrou o primeiro caso no Brasil. Até 1998, dos cerca de cem casos já relatados na literatura especializada, a maioria ocorreu no Caribe e no Brasil, e quase a metade estava relacionada à Martinica ${ }^{12}$. No Brasil, até o ano 1997, já somava 23 o número de casos ${ }^{1}$.

Na quase totalidade dos casos de parasitismo humano, apenas um casal é encontrado, e a maioria tem localização na traquéia e nos brônquios. Ocasionalmente são encontrados na rinofaringe e na laringe ${ }^{914}$.

\footnotetext{
1. Serviço de Infectologia, Hospital Universitário Cassiano Antônio Moraes, Universidade Federal do Espírito Santo, Vitória, ES. 2. Disciplina de Parasitologia, Departamento de Patologia do Centro de Ciências da Saúde, Universidade Federal do Espírito Santo, Vitória, ES.

Endereço para correspondência: Dr. Paulo Augusto Sessa. Rua Zacarias Fernandes Moça 230, 29075-180 Vitória, ES.

Tel: 5527 3335-7292

e-mail: paulo.sessa@gmail.com

Recebido para publicação em 12/12/2005

Aceito em 2/5/2007
} 


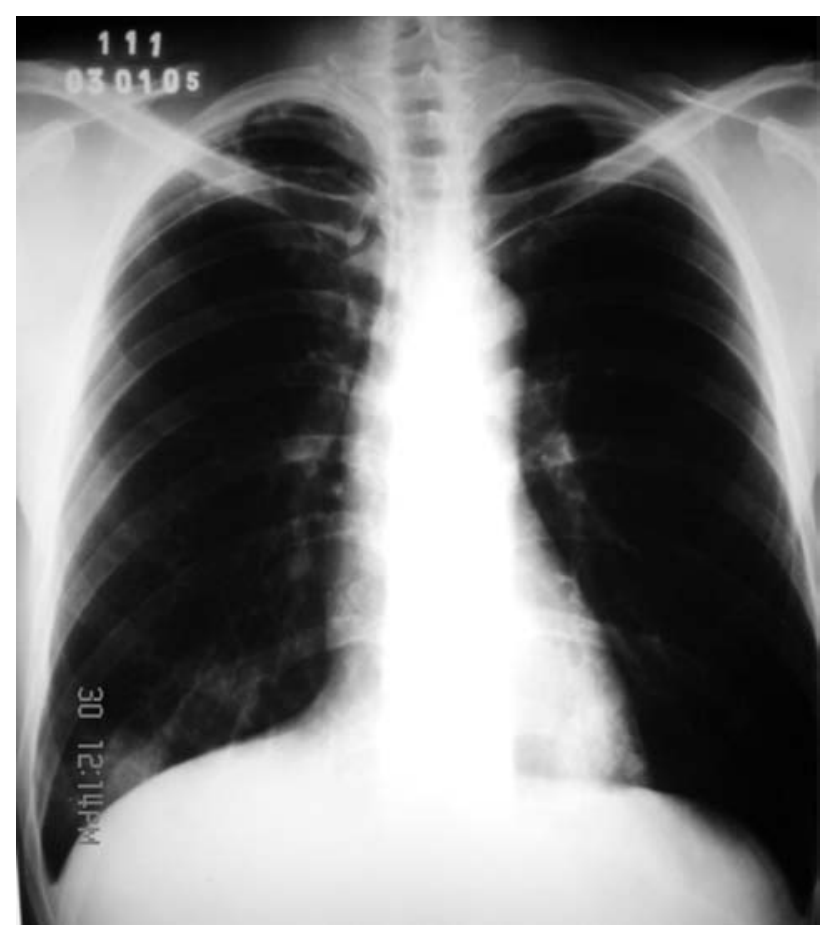

Figura 1 - Radiografia de tórax mostrando infiltrado peribrônquico paracardíaco à direita e em ápice pulmonar direito.
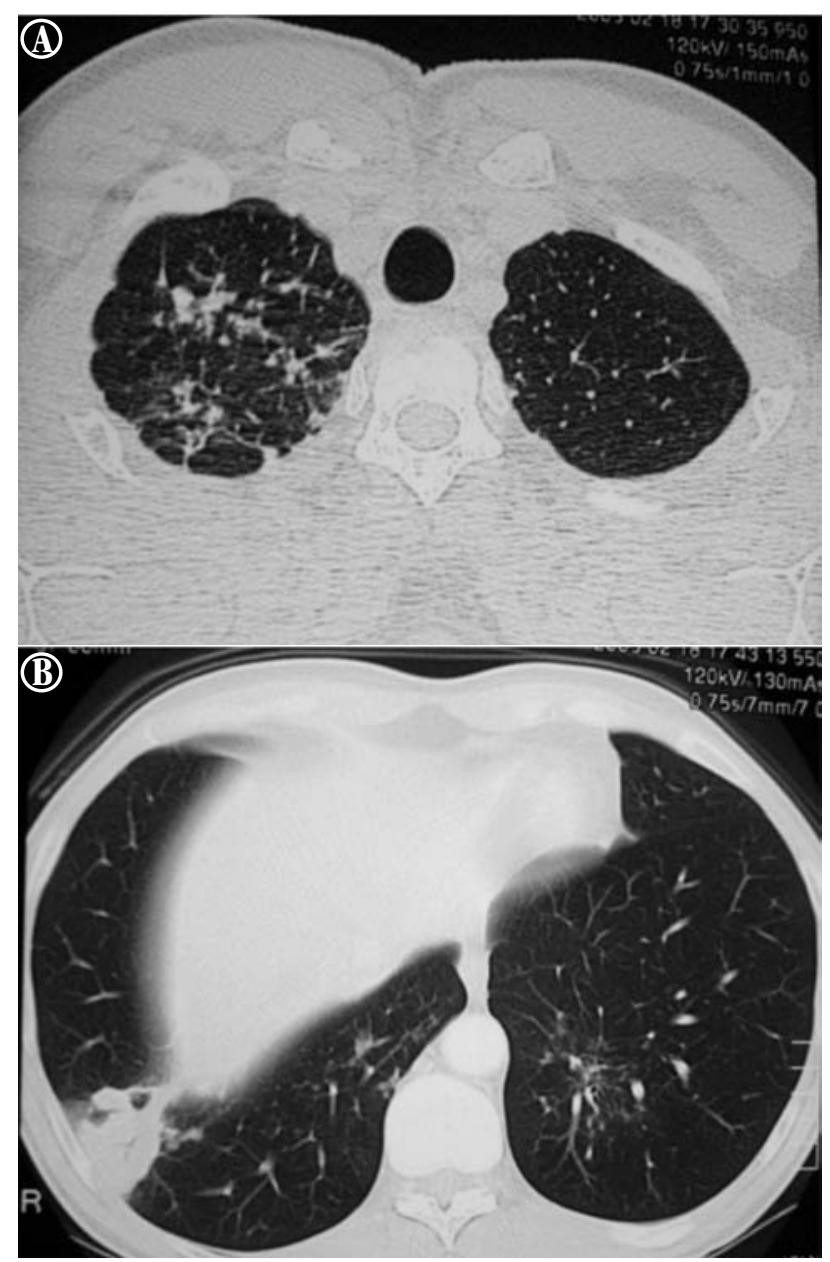

Figuras 2 - Tomografia computadorizada de tórax mostrando em A discretas bronquiectasias de permeio no lobo superior direito e em B processo pleuroparenquimatoso com espessamento septal e áreas de consolidação, estando a maior localizada no segmento basal posterior do pulmão direito.

\section{RELATO DO CASO}

Um paciente masculino, de 48 anos, agricultor e pecuarista no município de Águia Branca, Estado do Espírito Santo, iniciou, há 4 meses, um quadro pulmonar caracterizado por tosse seca predominantemente noturna e que se intensificava ao decúbito dorsal, associada à dor torácica retroesternal com irradiação para região dorsal, sudorese noturna e emagrecimento de seis quilos. Ao longo desse período teve dois episódios de escarros hemoptóicos. Até o final do terceiro mês, não havia apresentado febre. No quarto mês de evolução, entretanto, começou a apresentar picos febris diários de até $40^{\circ} \mathrm{C}$, associados a calafrios, delírios e dispnéia em repouso. Foi então que procurou atendimento médico em sua região e as suspeitas clínicas iniciais foram de tuberculose ou malária. Nenhuma dessas doenças pôde ser confirmada após quatro exames de escarro para pesquisa do bacilo de Koch e duas hematoscopias para pesquisa de plasmódios.

0 paciente foi então encaminhado ao Serviço de Infectologia do Hospital Universitário Cassiano Antônio de Moraes da Universidade Federal do Espírito Santo, onde foi internado para propedêutica diagnóstica. No exame físico de admissão, foram observadas as seguintes alterações: dor à compressão da região esternal, e abdome doloroso à palpação de hipocôndrio direito. Os exames dos aparelhos cardiovascular e respiratório mostraram-se normais. Não havia visceromegalias. Durante o exame, observou-se que o paciente apresentava paroxismos de tosse seca.

Foram realizados exames laboratoriais e de imagem com os seguintes resultados: hemograma: 15.000 leucócitos (7\% de neutrófilos bastões, 59\% de neutrófilos segmentados, 25\% de linfócitos, $8 \%$ de monócitos e $2 \%$ de eosinófilos), 12,3g/dl de hemoglobina, 37,8\% de hematócrito e 368.000 plaquetas; sangue: uréia $29 \mathrm{mg} / \mathrm{dl}$, creatinina $1 \mathrm{mg} / \mathrm{dl}$, sódio $142 \mathrm{mEq} / \mathrm{L}$, potássio $4 \mathrm{mEq} / \mathrm{L}$, cálcio iônico 4,79mEq/L; exame parasitológico de fezes: negativo; hemocultura e urocultura: negativas; ultrassonografia de abdome e ecocardiograma transtorácico: normais; radiografia de tórax: áreas de infiltrado como mostradas na Figura 1; broncofibroscopia: presença de organismo biológico vivo no brônquio do lobo superior esquerdo, móvel, de aspecto vermiforme, coloração vermelha e com forma de "Y", que foi retirado com auxílio de pinça de biópsia.

0 exame posterior desse ser vivo revelou tratar-se de um casal de $S$. laryngeus, medindo o macho 4,08mm de comprimento e a fêmea 11,75mm. Foram observados ovos no interior do útero da fêmea.

Poucas horas após à broncofibroscopia, realizou-se também tomografia computadorizada de tórax para melhor documentar o caso. Este exame revelou processo pleuro-parenquimatoso como mostrado nas Figuras 2A e 2B.

\section{DISCUSSÃO}

Apesar do parasitismo humano por $S$. laryngeus ser de ocorrência rara, os quadros clínicos cursam de forma muito semelhante. 0 sintoma constante a todos os pacientes é uma tosse 
crônica, quase sempre seca, que se manifesta por paroxismos e que se exacerba à noite. De forma inconstante, podem estar associados um ou mais dos seguintes sintomas: expectoração mucóide, escarro hemoptóico, escarro purulento, dor torácica, febre, dificuldade respiratória, crise de asma brônquica, sensação de corpo estranho móvel na garganta e na traquéia, disfonia ocasional, e dor, prurido e irritação da garganta 2457912141517.

0 exame clínico costuma ser normal, assim como o RX de tórax ${ }^{467}$, a exceção dos poucos casos nos quais existem processos inflamatórios da árvore traqueobrônquica ou do parênquima pulmonar's . No sangue, a eosinofilia também é inconstante ${ }^{5612}$. No caso descrito, 0 paciente apresentava alterações à tomografia computadorizada de tórax - processo pleuro-parenquimatoso com áreas de consolidação, localizado principalmente no segmento basal posterior do pulmão direito. Este processo inflamatório deveu-se, provavelmente, aos mediadores inflamatórios liberados nos locais de fixação e alimentação do helminto, associado a uma reação inflamatória desencadeada pelos antígenos do parasita adulto e de seus ovos.

Devido à raridade dos casos, não há suspeita clínica da doença. O diagnóstico é sempre parasitológico e feito principalmente durante uma broncofibroscopia, que acaba sendo indicada por ser o quadro de tosse refratária aos diversos tratamentos utilizados. Geralmente apenas um casal de vermes é encontrado e removido sob visualização direta 5791012 .

Também com certa frequiência, o diagnóstico é estabelecido quando o paciente elimina espontaneamente os vermes após um paroxismo severo de tosse $\mathrm{e}^{34681517}$. Outras vezes, o diagnóstico baseia-se no achado não intencional de ovos do verme no exame parasitológico de fezes, na secreção brônquica expectorada ou no sedimento do lavado traqueobrônquico $0^{617}$.

Os quadros clínicos regridem espontaneamente após os vermes serem removidos ou expectorados. Mesmo assim, alguns pacientes recebem tratamento com anti-helmínticos ${ }^{456}$

0 caso relatado cursou de forma semelhante aos demais citados na literatura e, não fosse tal doença de ocorrência rara, seria colocada entre os diagnósticos diferenciais de pacientes com paroxismos de tosse seca crônica.

\section{AGRADECIMENTOS}

Os autores agradecem ao doutor Walter dos Santos Lima, professor do Departamento de Parasitologia do Instituto de
Ciências Biológicas da Universidade Federal de Minas Gerais, pela confirmação diagnóstica do casal de parasitos.

\section{REFERÊNCIAS}

1. Atherino CCT, Silva PPC, Santos CF, Meirelles RC. Tosse Crônica de Origem Incomum: Relato de um Caso de Singamose Humana. Folha Médica 115 (supl 2): 117-119, 1997.

2. Birrel DJ, Moorhouse DE, Gardner MA, May CS. Chronic Cough and Hemoptysis due to a Nematode, Syngamus laryngeus. Australian New Zeland Journal of Medicine 8:168-170, 1978.

3. Freitas AL, Carli G, Blankenhein MH. Mammomonogamus (Syngamus) laryngeus infection: a new brazilian humam case. Revista do Instituto de Medicina Tropical de São Paulo 37: 177-179, 1995.

4. Grell GAC, Watty EI, Muller RL. Syngamus in a West Indian. British Medical Journal 11: 1464, 1978.

5. Kim HY, Lee SM, Joo JE, Na MJ, Ahn MH, Min DY. Human syngamosis: the first case in Korea. Thorax 53: 717-718, 1998.

6. Lara TAC, Barbosa MA, Oliveira MR, Godoy I, Queluz TT. Humam Syngamosis: two cases of Chronic Cough by Mammomonogamus laryngeus. Chest 103: 264-265, 1993.

7. Leers WD, Sarin MK, Arthurs K. Syngamosis, an unusual cause of asthma: the first reported case in Canada. Canadian Medical Association Journal 132: 269-270, 1985.

8. Leiper RT. Gapes in Man, an Occasional Helminthic Infection: a Notice of this Discovery by Dr. King in St. Lucia. Lancet 1:170, 1913.

9. Melo AL, Teixeira AS, Guerra AFM, Fortini MS, Fulgêncio MST. Parasitismo da rinofaringe pelo "Syngamus laryngeus". Jornal Brasileiro de Medicina 46: 94-95, 1984.

10. Mornex JF, Magdeleine J. Parasitic Pulmonary Disease: Human Bronchial Syngamosis. American Review Respiratory Disease 127:525-526, 1983.

11. Neves DP. Parasitologia Humana, $11^{\mathrm{a}}$ edição, Atheneu, São Paulo, 2004.

12. Nosanchuk JS, Wade SE, Landolf M. Case Report of and description of Parasite in Mammomonogamus laryngeus (Human syngamosis) infection. Journal of Clinical Microbiology 33: 998-1000, 1995.

13. Pessôa SB, Martins AV. Parasitologia Médica, $11^{\mathrm{a}}$ edição, Guanabara Koogan, Rio de Janeiro, 1988.

14. Pontes P, Gadelha ME, Gregório LC, Behlau M, Steffen N. Singamose laríngea: apresentação de dois casos. Revista Brasileira de Otorrinolaringologia 58: 294-297, 1992.

15. Santos VA, Villela MSH, Serra RG. Ocorrência de um novo caso de singamose humana em São Paulo, Brasil. Revista do Instituto de Medicina Tropical de São Paulo 28: 358-363, 1986.

16. Travassos L. Notas Helminthologicas. Brasil-Médico 35:67, 1921.

17. Weinstein L, Molavi A. Syngamus laryngeus infection (Syngamosis) with chronic cough. Annals of Internal Medicine 74: 577-580, 1971. 